\title{
Testing and modeling of Direct Seam Generating Parabolic Trough Collectors
}

\author{
Souha Ferchichi' ${ }^{1}$, Hamdi Kessentini ${ }^{1}$, Sergio Morales ${ }^{2}$, Lisa Willwerth ${ }^{4}$, João Soares ${ }^{3}$, Jesús \\ Castro $^{2}$, Chiheb Bouden', Armando Oliveira ${ }^{3}$, Ridha Ben Cheikh1 \\ ${ }^{1}$ Université Tunis el Manar, École Nationale d'Ingénieurs de Tunis,Tunis,(Tunisia). \\ 2 Technical University of Catalonia, Heat and Mass Transfer Technological center,Terrassa \\ Barcelone (Spain) \\ ${ }^{3}$ University of Porto- Faculty of Engineering,Porto (Portugal). \\ ${ }^{4}$ German Aerospace Center (DLR), Institute of Solar Research Cologne,Germany.
}

\begin{abstract}
The present work is elaborated in the framework of the REELCOOP research project. A mini hybrid (solar/biomass) power plant was installed and is under testing at ENIT (Ecole Nationale d'Ingénieurs de Tunis), Tunisia. The power plant relies on Parabolic Trough Collectors (PTC) operating with Direct Steam Generation (DSG), an Organic Rankine Cycle (ORC) for power generation, and a boiler as a backup system.

A general numerical model is developed to predict the thermal behavior of the two-phase flow in the PTC collector. The model is validated against experimental results carried out in DISS test facility and good agreement is found between the numerical and experimental results. The model is then used to investigate the performances of a PTC using hot water under Tunisian climatic conditions.

Preliminary tests of the REELCOOP installation were performed for solar only mode on August 2017 and the DSG was successfully demonstrated. The test results showed that the plant is able to produce steam up to $176^{\circ} \mathrm{C}$
\end{abstract}

Keywords: Parabolic Trough Collector, Direct Steam Generation, Performance analysis.

\section{Introduction}

Concentrating Solar Power (CSP) is one of the most promising electricity generation technologies especially in areas with abundant solar radiation and high electricity demand, such as North Africa (Salazar, 2008).CSP plants concentrate the solar radiation through their mirrors and reflect it on to a receiver using a thermal fluid as a Heat Transfer Fluid (HTF), exchanging heat with heat exchangers to generate steam and run a power cycle. Another perspective is to directly generate steam in the collectors, eliminating the need for heat transfer fluid in the solar field. This approach avoids the harmful effects of oils, improves the overall efficiency of the system by avoiding heat exchangers and therefore reduces the cost per kWh produced.(Birnbaum et al., 2011). One of the challenges DSG presents is the dynamic behavior, under the effect of the variation of the solar radiation, of the absorber tube in which the direct production of steam occurs. This issue is addressed in the framework of a European research project (REELCOOP), funded under the FP7 program, which aims at the demonstration, at ENIT university, of a small scale CSP plant with a capacity of $60 \mathrm{~kW}$ using a Rankine organic cycle turbine and PTCs $\left(1000 \mathrm{~m}^{2}\right)$ for direct steam production. This plant is equipped with a backup system using biomass (Oliveira and Coelho, 2013).

Different research studies including, modeling, simulation, and optimization of DSG in PTCs, have been carried out with the aim to predict the behavior of a direct steam generating PTC. The approaches included CFD models (Lobón et al., 2014b), steady state and transient models (Biencinto et al.,2016; Hachicha et al.,2018; Lobón and Valenzuela,2013; Odeh et al.,1998 and Odeh et al., 2000)and simulation tools 
(Aurousseau et al., 2015 ; Kurup et al., 2017 and Serrano-Aguilera and Valenzuela, 2016). The current developed model is based on solving the governing equations for the fluid flow, and applying the energy balance for the solid parts (receiver and glass envelope). The implementation of this approach is straightforward and it has a short simulation time. Besides, it predicts the flow behavior along the receiver tube with a good accuracy.

The main objectives of this work are: first to develop a thermal model taking into consideration the phase change as well as the transition between the different phases inside the PTC absorber tube; secondly, to simulate the performance of the PTC using hot water as HTF; thirdly, to present the DSG preliminary tests of REELCOOP facility. The developed model will serve as a future and fast practical tool to simulate the REELCOOP prototype solar field.

\section{Numerical Model Description}

The developed model is based on solving the governing equations (mass, momentum and energy) for the fluid flow inside the absorber tube, and applying the energy balance for the solid parts (absorber and glass envelope). The model applied for single phases was solved using the energy balance for the fluid flow and tube walls also. The heat transfer in a cross section of the Heat Collector Element (HCE) is shown in Fig.1.

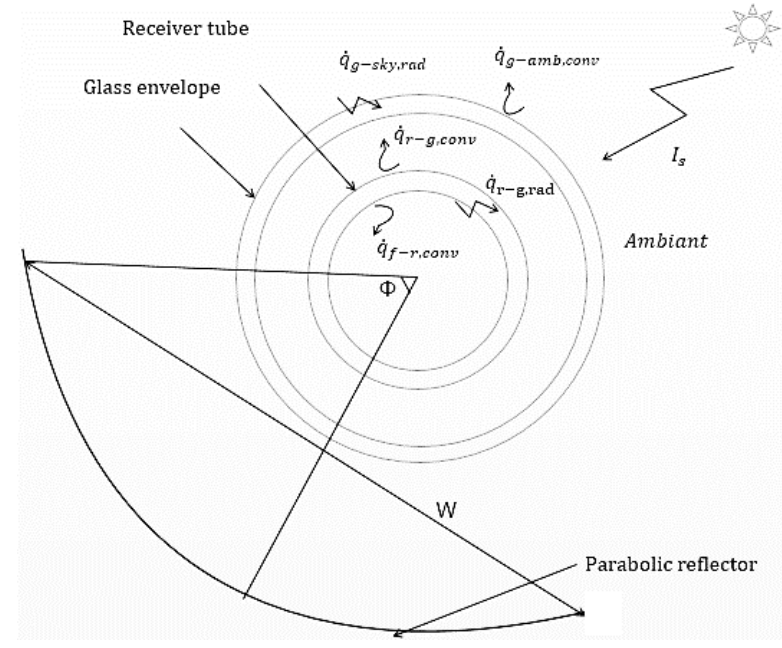

Fig. 1: Heat transfer in a cross section of a HCE

Most of the incoming solar radiation is absorbed by the receiver tube thanks to the high absorptance provided by its coating. A part of the absorbed energy is gained by the HTF inside the receiver tube, and the remaining is transmitted to the glass envelope by natural and forced convection. The heat losses from the glass envelope are in the form of convection to the ambient, and radiation to the sky (Forristall, 2003).

The energy balance equations are discretized between the HTF and the ambient by applying the Finite Volume Method (FVM) on the solar collector, and the set of the non-linear algebraic equations are solved using a step by step method.

The HCE is discretized in the axial direction, and the steady state energy balance for the receiver is expressed by:

$$
C \times \dot{q}_{r, \text { SolAbs }}=\dot{q}_{r-g, \text { conv }}+\dot{q}_{f-r, \text { conv }}+\dot{q}_{r-g, r a d}
$$

Where $\mathrm{C}$ presents the geometrical concentration factor and is expressed as follows:

$$
C=\frac{W-D_{r, e}}{\pi D_{r, e}}
$$

Similarly, the energy balance for the glass envelope is given by:

$$
\dot{q}_{r-g, \text { conv }}+\dot{q}_{f-r, \text { conv }}+\dot{q}_{g, \text { SolAbs }}=\dot{q}_{g-a, \text { conv }}+\dot{q}_{g-s k y, r a d}
$$


The heat transfer coefficients corresponding to the losses by convection and radiation are evaluated using empirical correlations.

The governing equations are discretized in the fluid flow axial direction as shown in Fig.2, while considering the flow to be steady state and separated. In fact, the liquid and vapor phase are considered to flow separately at different velocities.

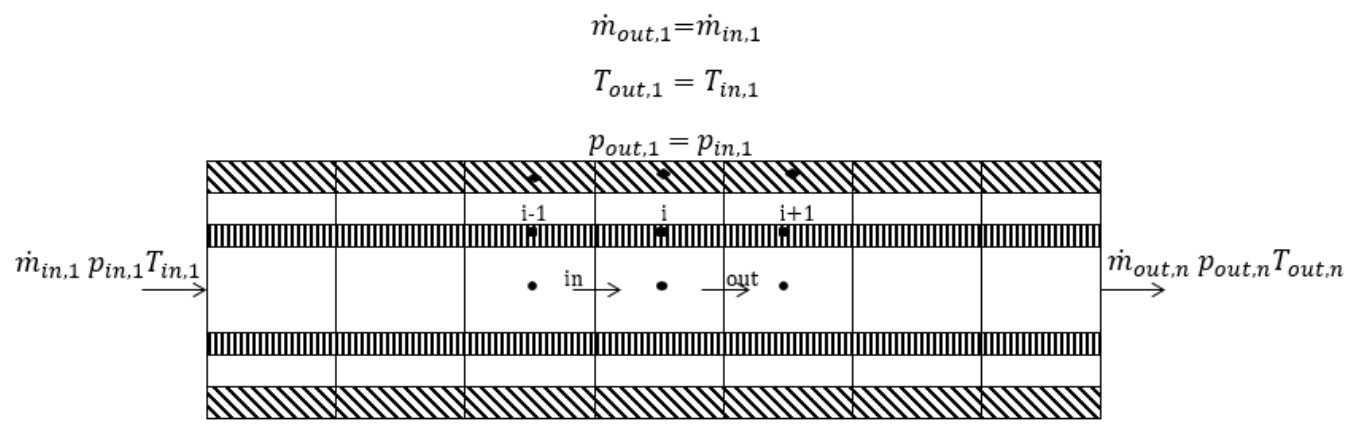

- Nodes for the fluid

- Nodes for the receiver

-Nodes for the glass envelope

Fig. 2: Discretization scheme of the calculation domain

The discretized continuity equation results in the outlet mass flow rate

$$
\dot{m}_{\text {in }}=\dot{m}_{\text {out }}=\dot{m}
$$

The discretized momentum equation is solved for the outlet pressure

$$
p_{\text {out }}=p_{\text {in }}-\frac{\Delta z}{A_{f}}\left(\left(\Phi \bar{f} \pi D_{r, i} \frac{\overline{\dot{m}}^{2}}{8 A_{f}^{2} \bar{\rho}_{t p}}+\frac{\left[\dot{m}\left(x_{g} v_{g}+\left(1-x_{g}\right) v_{l}\right)\right]_{\text {in }}^{\text {out }}}{\Delta z}\right)\right)
$$

The two-phase density is expressed as: $\rho_{t p}=\rho_{g} \varepsilon_{g}+\left(1-\varepsilon_{g}\right) \rho_{l}$

The liquid and vapor velocities are given by: $v_{g, \text { out }}=\left[\frac{\dot{m} x}{\rho_{v} \varepsilon_{g} A_{f}}\right]_{\text {out }} ; v_{l, \text { out }}=\left[\frac{\dot{m}(1-x)}{\rho_{l}\left(1-\varepsilon_{g}\right) A_{f}}\right]_{\text {out }}$

The discretized energy equation is solved for the outlet enthalpy

$$
H_{\text {out }}=\frac{2 \dot{q}_{\text {wall }} \pi D_{\text {rint }} \Delta x-\dot{m}_{\text {out }} a 1+\dot{m}_{\text {in }} a 2}{\dot{m}_{\text {out }}+\dot{m}_{\text {in }}}
$$

$a 1=\left(x v_{g}+(1-x) v_{l}\right)_{\text {out }}^{2}-H_{\text {in }}$

$a 2=\left(x v_{g}+(1-x) v_{l}\right)_{i n}^{2}+H_{i n}$

Where: $\dot{q}_{\text {wall }}=h\left(T_{r}-T_{f}\right)$

The thermodynamic properties of the fluid are introduced in the form of equations, and the fluid temperatures as well as equilibrium quality are calculated using the NIST database for water, as a function of pressure and enthalpy.

The equilibrium quality is given by (Kandlikar, 1991):

$$
x=\frac{H-H_{l}}{H_{g}-H_{l}}
$$




\subsection{Single phase flow empirical correlations}

The heat transfer coefficient in the single phase flow is evaluated using the correlation of Gnielinski and Petukhov (Gnielinski, 1975; Kandlikar, 1991; Petukhov and Popov, 1963). The choice of the correlation is based on the flow regime (laminar or turbulent). Besides Churchill correlation is adopted for the calculation of the friction factor (Churchill, 1977).

\subsection{Two-phase flow correlations}

Kandlikar (Kandlikar, 1990) correlation is used to evaluate the two phase heat transfer coefficient. The method presents two expressions taking into consideration convective and nucleate boiling, and the heat transfer coefficient is calculated according to the dominant heat transfer process.

The void fraction is calculated using Zivi (Zivi, 1964) correlation, for separated flow models, the friction factor is evaluated using the same correlation as in the single phase region, and the two phase multiplier $\Phi$ which is evaluated by means of the Friedel (Friedel, 1979) .

\section{Numerical algorithm}

The model relies on dividing the absorber tube into a finite number of elements and evaluating the fluid outlet temperature, pressure, enthalpy, quality, heat loss, thermal efficiency, heat gain and the useful energy. The solution process is programmed in c++ language. Initially, the geometrical and optical parameters of the PTC, the meteorological data, the fluid inlet conditions (temperature, pressure, mass flow etc), are introduced as input data to the algorithm in one hand, and the temperature and pressure distribution for the components of the HCE are initialized in the other hand.

As a following step, the thermodynamic and transport properties of the HTF and the annulus gas are computed to evaluate heat transfer coefficients and the heat fluxes defined in the previous section (section 2).

For each element, the governing equations and the energy balance equations are solved, and the outlet variables values are set equal to the inlet variables of the next element.

\section{Validation results}

The validation of the developed numerical model was validated for single-phase flow using Syltherm oil, water and superheated steam, and for two-phase flow predicting the DSG inside the receiver tubes.

Firstly, the model was validated for the case of PTC with Syltherm oil and hot water using experimental results carried out at Sandia National Laboratories (SNL) (Dudley et al., 1994) for a SEGS LS2 collector.

The numerical and experimental results, of Syltherm oil as HTF, are presented in Fig.3. The thermal efficiency and the heat losses from the HCE are illustrated as a function of the temperature above ambient defined as: $\Delta T-T_{a}$, where $\Delta T=T_{o}-T_{i}$.

The validation was carried out for two types of receiver coatings (cermet and black chrome), and for vacuum and air in the gap between the receiver and the glass envelope.

The fluid outlet temperature and thermal efficiency in case of water as HTF are presented in Tab.1. The numerical results show good agreement with the experimental measurements. The mean relative errors obtained for the thermal efficiency are $1.5 \%$ in the case of vacuum in the annular space and $1.35 \%$ in the case of air. As for the heat losses, the mean relative errors obtained are $13.8 \%$ and $3.2 \%$ for vacuum and air in the annular space respectively. 

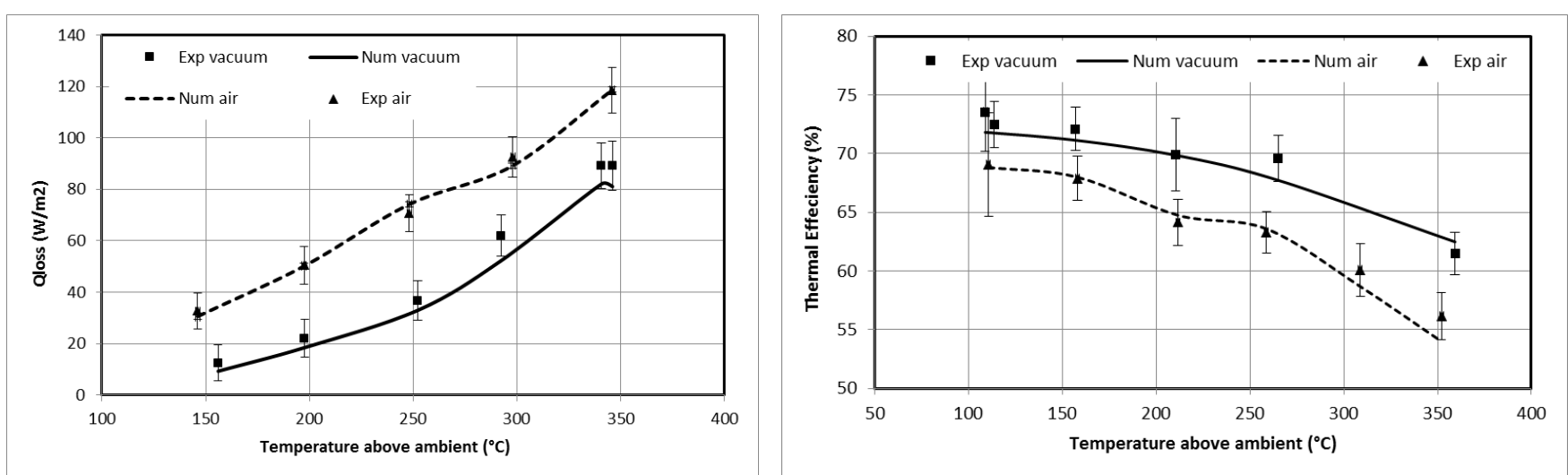

Fig. 3: Numerical (Num) and experimental (Exp) results of thermal efficiency and heat losses using synthetic oil

Tab. 1: Validation table for hot water (Dudley et al., 1994)

\begin{tabular}{|c|c|c|c|c|c|c|c|c|c|c|c|}
\hline $\begin{array}{c}\text { DNI } \\
\left(\mathbf{W ~ m ~}^{-2}\right)\end{array}$ & $\begin{array}{c}\text { Pressure } \\
(\mathbf{M P a})\end{array}$ & $\begin{array}{c}\text { Ambient } \\
\mathbf{T} \\
(\mathbf{K})\end{array}$ & $\begin{array}{c}\text { Wind } \\
\text { velocity } \\
\left(\mathbf{m ~ s ~ s}^{-1}\right)\end{array}$ & $\begin{array}{c}\text { Mass } \\
\mathbf{f l o w} \\
\left(\mathbf{k g ~ s}^{-1}\right)\end{array}$ & $\boldsymbol{T}_{\boldsymbol{i}}(\mathbf{K})$ & $\eta_{\text {th }}$ & $\eta_{\text {th,exp }}$ & $\begin{array}{c}\eta_{t h} \mathbf{E r r} \\
\mathbf{\%}\end{array}$ & $\boldsymbol{T}_{\boldsymbol{o}}(\mathbf{K})$ & $\begin{array}{c}\boldsymbol{T}_{\boldsymbol{o}, \text { exp }} \\
(\mathbf{K})\end{array}$ & $\begin{array}{c}\boldsymbol{T}_{\boldsymbol{o}} \mathbf{E r r} \\
\mathbf{\%}\end{array}$ \\
\hline 807.5 & 0.1 & 288.95 & 1 & 0.306 & 291.45 & 0.68 & 0.73 & 6.48 & 308.65 & 309.25 & 0.19 \\
\hline
\end{tabular}

The superheated steam numerical results were validated against experimental results carried out in DISS test facility for an LS3 collector with a 4.06 m tube length (Serrano-Aguilera et al., 2014).

Tab.2: Validation table for superheated steam (Serrano-Aguilera et al., 2014)

\begin{tabular}{|c|c|c|c|c|c|c|c|c|c|c|c|}
\hline $\begin{array}{c}\text { DNI } \\
\left(\begin{array}{c}\text { W m } \\
\text { 2) }\end{array}\right.\end{array}$ & $\begin{array}{c}\text { Pressure } \\
\text { (MPa) }\end{array}$ & $\begin{array}{c}\text { Ambient } \\
\mathbf{T} \\
(\mathbf{K})\end{array}$ & $\begin{array}{c}\text { Wind } \\
\text { velocity } \\
\left(\mathrm{m} \mathrm{s}^{-1}\right)\end{array}$ & $\begin{array}{c}\text { Mass } \\
\text { flow } \\
\left(\mathrm{kg} \mathrm{s}^{-1}\right)\end{array}$ & $\boldsymbol{T}_{\boldsymbol{i}}(\mathbf{K})$ & $\eta_{t h}$ & $\eta_{t h, e x p}$ & $\underset{\%}{\eta_{t h} \operatorname{Err}}$ & $\begin{array}{c}T_{o} \\
(\mathbf{K})\end{array}$ & $\begin{array}{c}T_{o, \exp } \\
(\mathbf{K})\end{array}$ & $\underset{\%}{T_{o} \operatorname{Err}}$ \\
\hline 921 & 6.188 & 303.3 & 0.5 & 0.64 & 560 & 0.58 & 0.64 & 10.11 & 564.17 & 565.00 & 0.15 \\
\hline 804 & 6.125 & 307.2 & 0.5 & 0.53 & 551.6 & 0.57 & 0.65 & 11.61 & 555.83 & 556.50 & 0.12 \\
\hline 771 & 3.237 & 309.6 & 0.5 & 0.52 & \begin{tabular}{|l|l}
532.8 \\
\end{tabular} & 0.58 & 0.62 & 6.81 & 538.61 & 539.90 & 0.24 \\
\hline 790 & 3.223 & 307.9 & 0.5 & 0.5 & 527.8 & 0.58 & 0.64 & 9.53 & 533.95 & 535.10 & 0.22 \\
\hline 853 & 10.085 & 307 & 0.5 & 0.58 & 616.5 & 0.56 & 0.52 & 7.38 & 619.92 & 620.40 & 0.08 \\
\hline 823 & 6.113 & 305.6 & 0.5 & 0.53 & 585.5 & 0.57 & 0.62 & 8.67 & 590.39 & 592.10 & 0.29 \\
\hline 910 & 5.854 & 299 & 0.5 & 0.64 & 576 & 0.57 & 0.58 & 1.46 & 580.52 & 581.40 & 0.15 \\
\hline 804 & 3.161 & 301.8 & 0.5 & 0.53 & 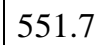 & 0.57 & 0.6 & 4.31 & 557.88 & 559.20 & 0.24 \\
\hline
\end{tabular}

At the outlet of the PTC tube, the calculated temperature and thermal efficiency $\left(\eta_{t h}\right)$ are evaluated and compared to the DISS experimental data. A mean relative error of $7.5 \%$ is obtained for the thermal efficiency, and $0.18 \%$ for the outlet temperature.

Finally, the DSG numerical model, predicting the phase change and the heat transfer in the PTC, was validated against experimental measurements from DISS facility (Lobón et al., 2014a), and the outlet pressure and temperature are displayed as a function of the receiver length in Fig 4, for the inlet conditions reported in Tab 3. 
Tab. 3 Inlet conditions for a DISS test case (Lobón et al., 2014a)

\begin{tabular}{|c|c|c|c|}
\hline $\mathbf{P}_{\text {in }}(\mathbf{M P a})$ & $\mathbf{T}_{\text {in }}\left({ }^{\circ} \mathbf{C}\right)$ & $\dot{\mathbf{m}}_{\text {in }}(\mathbf{k g} / \mathbf{s})$ & DNI $\left(\mathbf{W} / \mathbf{m}^{\mathbf{2}}\right)$ \\
\hline 3.38 & 196 & 0.47 & 807 \\
\hline
\end{tabular}

As can be seen in Fig.4, the obtained numerical results are in good agreement with the experimental ones, and the mean relative errors for the outlet pressure and temperature are $0.55 \%$ and $5.42 \%$ respectively. The highest discrepancies are noticed in the superheating section, where the model tends to over predict the outlet temperature. These discrepancies may due the heat transfer coefficients correlations used in the superheating section.
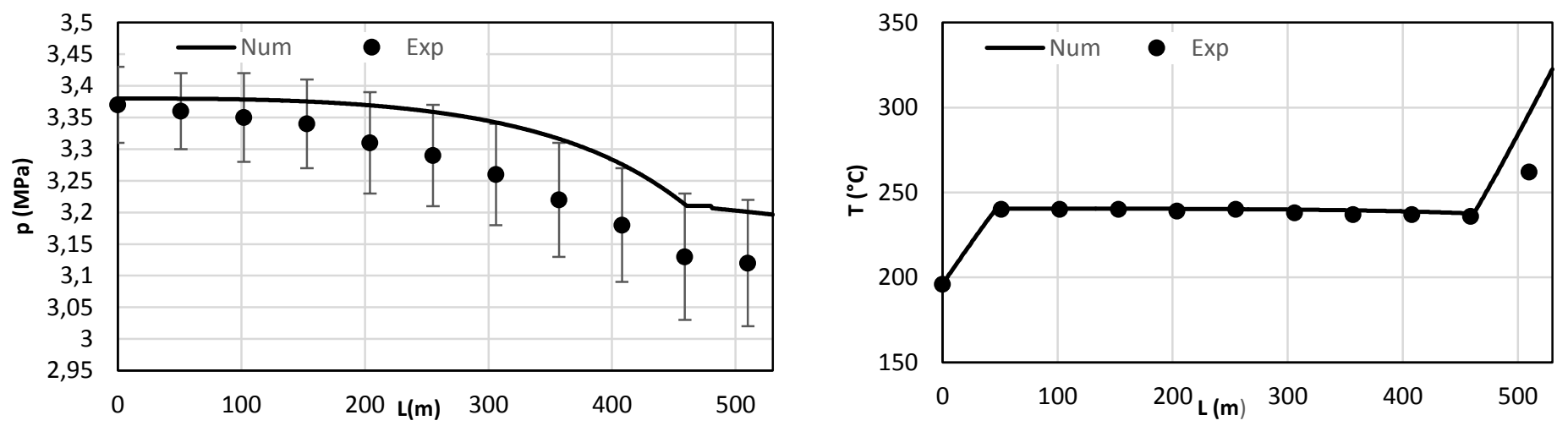

Fig. 4: Numerical vs experimental results of the DSG model, for the outlet pressure (left) and temperature (right)

The DSG model developed is general and includes all three phases, as well as the dryout regime, which can occur at the end of the saturated two-phase region. The model will be applied on the PTC of REELCOOP installation to evaluate its performance. Only saturated steam is generated in the installation. and so the liquid, and saturated phases only will be needed for the simulations. Besides, the REELCOOP prototype relies on recirculation mode to prevent any dryout that may occur in the receiver tube. Thus, the dryout part will be excluded as well.

\section{Performance analysis with Hot water}

The developed model for single phase flow is used to simulate a PTC generating hot water. Two typical days in summer and winter were chosen for the simulations. The heat gain by the HTF is evaluated in both cases and illustrated in Fig.5 along with the DNI, ambient temperature and wind speed.

We conclude from the graphs that the PTC can be operational for an average of 10 hours during the summer with a maximum heat gain of $626 \mathrm{~W} / \mathrm{m}^{2}$, and 7 hours during winter, with $318 \mathrm{~W} / \mathrm{m}^{2}$ as maximum heat gain. 

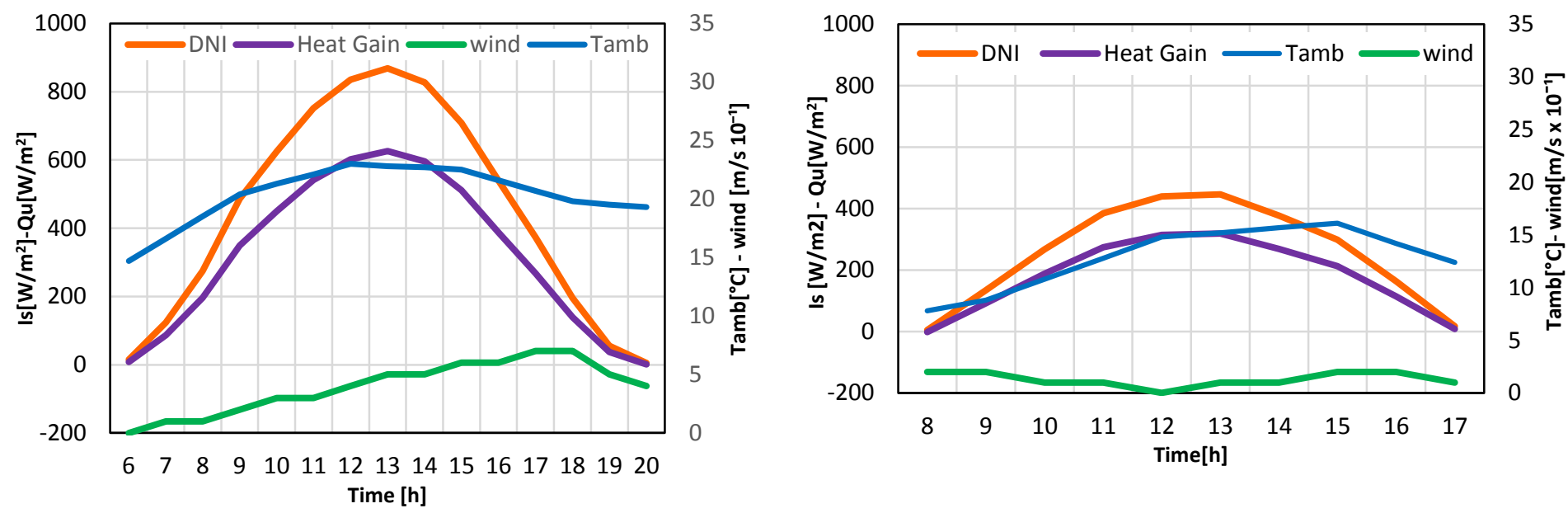

Fig.5: Hourly useful heat per unit of aperture area of the PTC in June (left), and December (right)

\section{Commissioning and testing of REELCOOP facility}

The prototype implemented in Tunisia relies on parabolic trough collectors and an organic Rankine cycle (ORC) enhanced by a biogas boiler. It is currently under installation at the École Nationale d'Ingénieurs de Tunis (ENIT) in Tunisia. This installation will then be used for demonstration, and for training students on the involved renewable technologies.

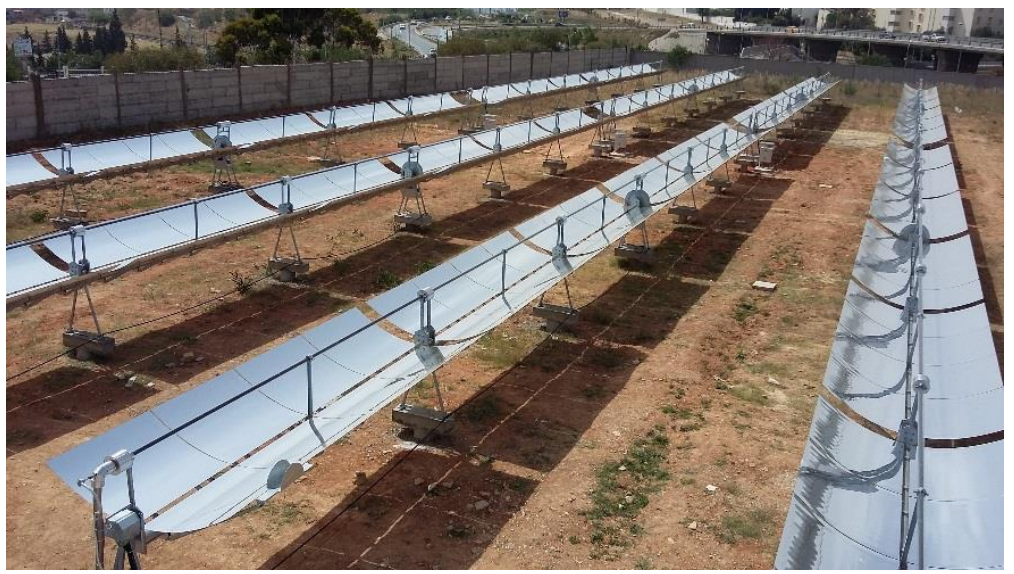

Fig.6: Solar field of REELCOOP plant

\subsection{REELCOOP mini power plant technical description}

The plant uses a completely innovative approach which is the hybridization of renewable resources: solar and biomass. It consists of three parallel rows of parabolic troughs with a net collecting surface of $1000 \mathrm{~m}^{2}$ (Fig.6) operating in direct steam generation (DSG) concept, and generating saturated steam at $175{ }^{\circ} \mathrm{C} / 8.9$ bar. The Organic Rankine Cycle (ORC) turbine with a newly developed generator design generates up to $65 \mathrm{~kW}$ electrical from low temperature steam produced by the solar field, with a nominal gross efficiency reaching 14\%. Biomass anaerobic digestion and phase change storage are demonstrated as well (Krüger et al., 2017). Fig.7 illustrates the P\&ID of the DSG closed loop in REELCOOP plant. 


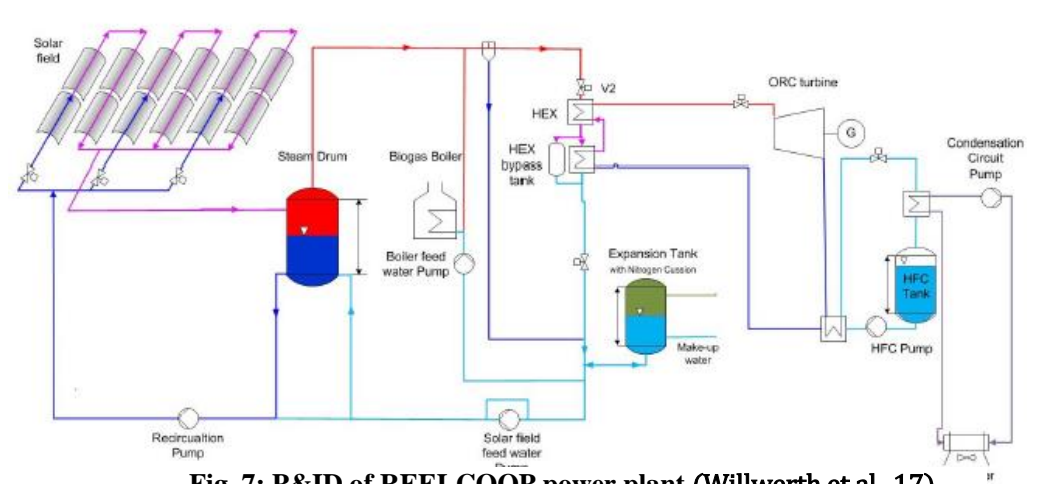

Fig. 7: P\&ID of REELCOOP power plant (Willwerth et al., 17)

The solar collectors are oriented in a North-South direction and they track the sun throughout the day from East to West. The curved shapes send most of the heat collected from the sun to a receiver placed on the focal line and generate the steam directly. Subcooled water at a temperature of $148^{\circ} \mathrm{C}$ is pumped to the solar field. In the first collector of each loop the whole water flow is heated up by the radiation of the sun. The water is partially evaporated in the remaining segment of the collector loop. Downstream the evaporation section, a steam drum is placed to separate steam from water. The steam is sent off to the turbine to spin a generator, after it is condensed and sub-cooled in the ORC heat exchangers to $80^{\circ} \mathrm{C}$ and finally pumped back by the feed water pump.

Before leaving the steam drum. the water coming from the solar field at $175{ }^{\circ} \mathrm{C}$ mixes with subcooled water at $80^{\circ} \mathrm{C}$ and is then recirculated back to the solar field by a recirculation pump.

\subsection{Preliminary test results}

The commissioning and testing of the plant took place at ENIT for solar only mode, started the $21^{\text {st }}$ of August, 2017 and lasted five days. The solar field was firstly tested with low temperatures, and then was operated in part load for steam generation. The PTCs produced steam at approximately $177^{\circ} \mathrm{C} / 8.3$ bars. All the data of the solar field and the whole plant are sent to a control and data acquisition system for a good monitoring of the facility.

One of the main purposes of the tests was to detect the steam generation in the solar field. Two view-glass were implemented in the installation including one between the solar field and the steam drum. Different flow regimes are depicted in Fig.8.

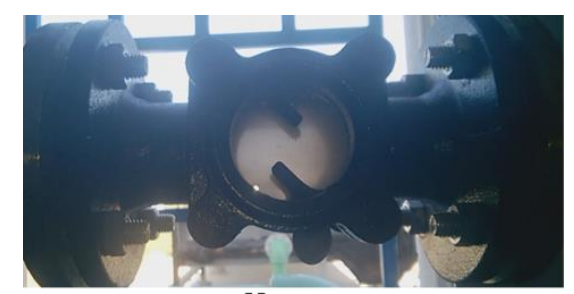

Hot water

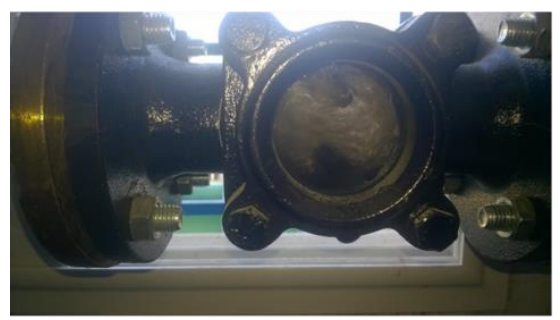

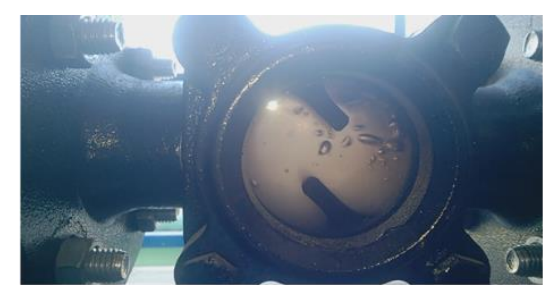

Bubble formation

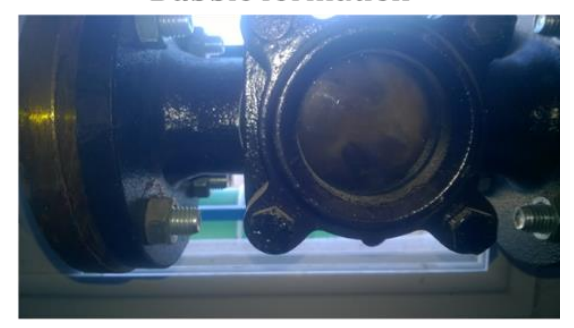

Liquid + vapor mixture

Fig 8: flow regimes at the outlet of the solar field 
Three sets of results for three different days were obtained (e.g.: August 21. 22 and 23. 2017). The data set includes the inlet and outlet temperature pressure and mass flow at the plant's different components. In this paper, we will present the solar field results obtained.

The solar only mode test results on August 21.2017 are presented in Fig.9. On the right part of the figure, the inlet and outlet temperature and pressure are displayed, and on the left part, the acquisition system with the corresponding sensors implemented in the solar field.

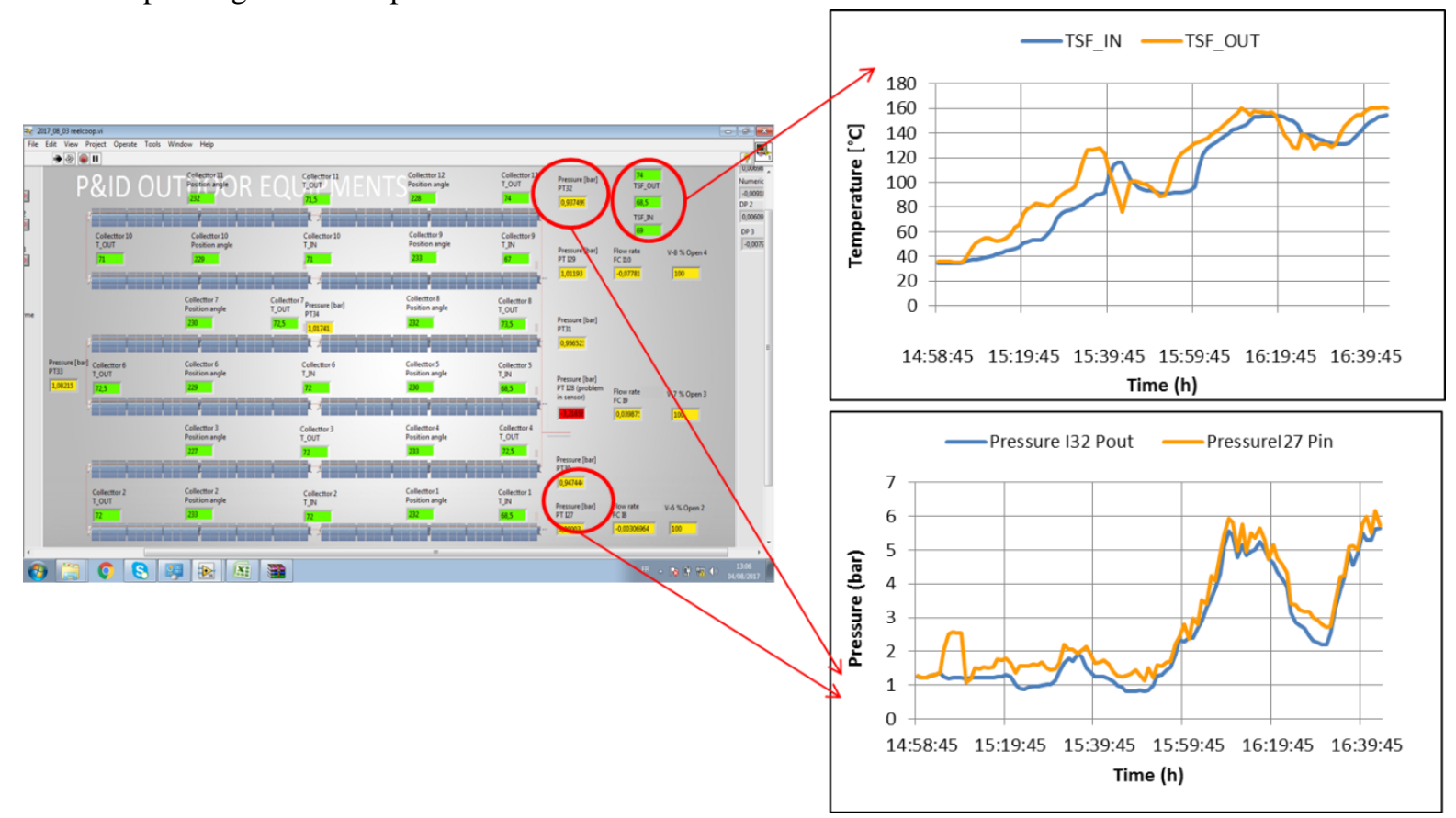

Fig. 9: August 21 ${ }^{\text {st }}, 2017$ solar field test results

The data shown was registered between $11 \mathrm{am}$ and $5 \mathrm{pm}$ (Fig.10) on the second day of the tests. The chart of DNI shows the DNI on the collector. When the collector is defocused, the DNI graph falls to zero. As noticed, both temperature (TSF_OUT) and pressure (Pout) keep increasing with time as soon as the collector is focused. The sudden decrease in temperature and pressure is explained by a defocus of the collectors. Since it was the first time operating the plant, the collectors were defocused several times during the tests in order to control the overheating, and also in order to follow the behavior of the phase change closely. As can be noted from the graph, once the solar field is focused, the temperature of the fluid rises quickly to reach $177^{\circ} \mathrm{C}$ at around 4:20 PM.

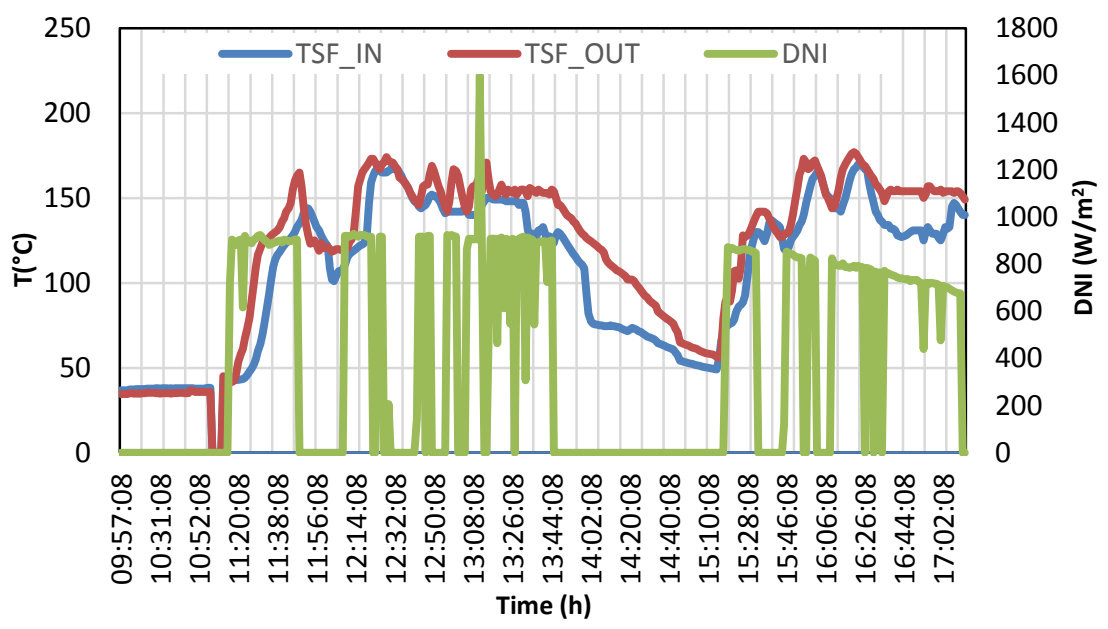

Fig 10 August 22 ${ }^{\text {nd }}, 2017$ solar field test results 


\section{Conclusion}

The current work presents a DSG model to predict the phase change and the heat transfer in a PTC. The model is based on solving the governing equations for the fluid flow and the energy balance for the tube walls. The validation was carried out for single phase flow using Syltherm oil, water and superheated steam as a first step. The model was then validated for single phase (water and steam) and two-phase fluid against DISS test facility measurements. The numerical results proved that the model is capable of predicting the experimental performance with good accuracy. As a second part of the work, the preliminary tests of a mini power plant PTC installed at ENIT, Tunisia were presented. Overall, three test day results were obtained. Even though the plant was operated in part load, the steam was successfully generated and the temperature at the solar field outlet reached $177{ }^{\circ} \mathrm{C}$ and higher. The developed numerical model will be used to simulate the REELCOOP PTC, while considering only the liquid and saturated phases. Performance analysis will be carried out under Tunisian climatic conditions, in order to prove the feasibility of implementing PTC relying on DSG in Tunisia, and in the Mediterranean region.

\section{Acknowledgment}

This work has been financed by REELCOOP project which receives funding from the European Union Seventh Framework Programme (FP7/2007-2013), under grant agreement no. 608466. S.Ferchichi also wishes to thank ERASMUS+KA107 programme for its support in the form of a doctoral scholarship.

\section{References}

Aurousseau, A., Vuillerme, V., Bezian, J.-J., 2015. Modeling of Linear Concentrating Solar Power using Direct Steam Generation with Parabolic Trough, Proceedings of the 11th International Modelica Conference, Versailles, France, September 21-23, 2015. Linköping University Electronic Press, pp. 595-603. http://www.ep.liu.se/ecp/118/064/ecp15118595.pdf

Biencinto, M., González, L., Valenzuela, L., 2016. A quasi-dynamic simulation model for direct steam generation in parabolic troughs using TRNSYS. Appl. Energy 161, 133-142. doi: 10.1016/j.apenergy.2015.10.001

Birnbaum, J., Feldhoff, J.F., Fichtner, M., Hirsch, T., Jöcker, M., Pitz-Paal, R., Zimmermann, G., 2011. Steam temperature stability in a direct steam generation solar power plant. Sol. Energy 85, 660-668. Churchill, S.W., 1977. Friction-factor equation spans all fluid-flow regimes. Chem. Eng. 84, 91-92. doi:10.1016/j.solener.2010.10.005

Dudley, V., Kolb, G., Sloan, M., Kearney, D., 1994. SEGS LS2 solar collector-test results. Rep. Sandia Natl. Lab. Rep. No SANDIA94-1884.

http://large.stanford.edu/publications/coal/references/troughnet/solarfield/docs/segs_ls2_solar_collector.pdf

Forristall, R., 2003. Heat transfer analysis and modeling of a parabolic trough solar receiver implemented in engineering equation solver. National Renewable Energy Lab., Golden, CO. (US). doi: 10.2172/15004820

Friedel, L. (1979). Improved Friction Pressure Drop Correlations for Horizontal and Vertical Two-Phase Pipe Flow. ROHRE - ROHRELEITUNGSBAU - ROHRELEITUNGSTRANSPORT. 18. 485-491. https://ci.nii.ac.jp/naid/80000503954/

Gnielinski, V., 1975. Neue Gleichungen für den Wärme- und den Stoffübergang in turbulent durchströmten Rohren und Kanälen. Forsch. Im Ingenieurwesen A 41, 8-16. doi: 10.1007/BF02559682

Hachicha, A.A., Rodríguez, I., Ghenai, C., 2018. Thermo-hydraulic analysis and numerical simulation of a parabolic trough solar collector for direct steam generation. Appl. Energy 214, 152-165.

doi: 10.1016/j.apenergy.2018.01.054 
Kandlikar, S.G., 1990b. A general correlation for saturated two-phase flow boiling heat transfer inside horizontal and vertical tubes. ASME J Heat Transf. 112, 219-228. doi:10.1115/1.2910348

Kandlikar, S.G., 1991. Development of a flow boiling map for subcooled and saturated flow boiling of different fluids inside circular tubes. J. Heat Transf. 113, 190-200. doi:10.1115/1.2910524

Krüger, D., Willwerth, L., Dathe, S., 2017. Research Cooperation in Renewable Energy Technologies for Electricity Generation REELCOOP Report on commissioning and testing. German Aerospace Center DLR.

Kurup, P., Parikh, A., Möllenkamp, J., Beikircher, T., Samoli, A., Turchi, C., n.d. SAM process heat model development and validation : liquid-HTF trough and Direct Steam Generation linear focus systems. Int. Conf. Sol. Heat. Cool. Build. Ind. 29 OCT-02-NOv 2017 Abu Dhabi UAE. doi: 10.18086/swc.2017.26.06

Lobón, D.H., Baglietto, E., Valenzuela, L., Zarza, E., 2014a. Modeling direct steam generation in solar collectors with multiphase CFD. Appl. Energy 113, 1338-1348. doi: /10.1016/j.apenergy.2013.08.046

Lobón, D.H., Valenzuela, L., 2013. Impact of pressure losses in small-sized parabolic-trough collectors for direct steam generation. Energy 61, 502-512. doi: /10.1016/j.energy.2013.08.049

Lobón, D.H., Valenzuela, L., Baglietto, E., 2014b. Modeling the dynamics of the multiphase fluid in the parabolic-trough solar steam generating systems. Energy Convers. Manag. 78, 393-404.

doi: 10.1016/j.enconman.2013.10.072

Odeh, S.D., Behnia, M., Morrison, G.L., 2000. Hydrodynamic analysis of direct steam generation solar collectors. J. Sol. Energy Eng. 122, 14-22. doi:10.1115/1.556273

Odeh, S.D., Morrison, G.L., Behnia, M., 1998. Modelling of parabolic trough direct steam generation solar collectors. Sol. Energy 62, 395-406. doi: 10.1016/S0038-092X(98)00031-0

Oliveira, A.C., Coelho, B., 2013. REELCOOP project: developing renewable energy technologies for electricity generation, in: 12th International Conference on Sustainable Energy Technologies (SET2013). Hong Kong. http://www.reelcoop.com/admin/content/news/paper_set2013_reelcoop_en_1385484468.pdf

Petukhov, B.S., Popov, V.N., 1963. Theoretical calculation of heat exchange and frictional resistance in turbulent flow in tubes of an incompressible fluid with variable physical properties(Heat exchange and frictional resistance in turbulent flow of liquids with variable physical properties through tubes). High Temp. 1, 69-83.https://ci.nii.ac.jp/naid/10011325838/

Salazar, C.M., 2008. An overview of csp in europe, north africa and the middle east. CSP Today. http://www.csptoday.com/reports/CSPinEU\&MENA.pdf

Serrano-Aguilera, J.J., Valenzuela, L., 2016. Transient validation of RELAP5 model with the DISS facility in once through operation mode, in: AIP Conference Proceedings. AIP Publishing, p. 040006. doi : $10.1063 / 1.4949097$

Serrano-Aguilera, J.J., Valenzuela, L., Parras, L., 2014. Thermal 3D model for direct solar steam generation under superheated conditions. Appl. Energy 132, 370-382. doi: 10.1016/j.apenergy.2014.07.035

Zivi, S.M., 1964. Estimation of steady-state steam void-fraction by means of the principle of minimum entropy production. J. Heat Transf. 86, 247-251. doi:10.1115/1.3687113 


\section{Units and Symbols}

\begin{tabular}{lll}
\hline Quantity & Symbol & Unit \\
\hline Cross section area & $\mathrm{A}$ & $\mathrm{m}^{2}$ \\
Concentration factor & $\mathrm{C}$ & - \\
Diameter & $\mathrm{D}$ & $\mathrm{m}$ \\
Density & $\rho$ & $\mathrm{kg} \mathrm{m}^{-3}$ \\
Enthalpy & $\mathrm{H}$ & $\mathrm{J} \mathrm{kg}^{-1}$ \\
Equilibrium quality & $\mathrm{X}$ & - \\
Efficiency & & $\mathrm{\eta}$ \\
Friction factor & $\mathrm{f}$ & - \\
Heat flux & $\dot{\mathrm{q}}$ & $\mathrm{W} \mathrm{m}{ }^{-2}$ \\
Mass flow & $\dot{\mathrm{m}}$ & $\mathrm{kg} \mathrm{s}^{-1}$ \\
Pressure & $\mathrm{p}$ & $\mathrm{MPa}$ \\
Temperature & $\mathrm{K}$ & $\mathrm{T}$ \\
velocity & $\mathrm{v}$ & $\mathrm{m} \mathrm{s}$ \\
Void fraction & $\varepsilon$ & - \\
Width & $\mathrm{W}$ & $\mathrm{m}$ \\
\hline
\end{tabular}

\begin{tabular}{ll}
\hline Subscript & Symbol \\
\hline Ambient & $\mathrm{a}$ \\
Convection & conv \\
Experimental & exp \\
Fluid & $\mathrm{f}$ \\
Glass envelope/vapor & $\mathrm{g}$ \\
Inlet & in \\
Inner & $\mathrm{i}$ \\
Outer & $\mathrm{e}$ \\
Liquid & $\mathrm{l}$ \\
Outlet & out \\
Receiver & $\mathrm{r}$ \\
Radiation & rad \\
Absorbed solar radiation & SolAbs \\
Thermal & th \\
\hline
\end{tabular}

